\title{
TRES MOMENTOS DE LOS MOVIMIENTOS REVOLUCIONARIOS VISTOS EN LA LITERATURA LATINOAMERICANA: BENEDETTI, ARGUETA Y VARGAS LLOSA $^{1}$
}

\author{
Jorge Chen Sham
}

\begin{abstract}
RESUMEN
La literatura latinoamericana grafica la repercusión de los grupos guerrilleros mediante un milenarismo que anuncia el caos y la destrucción y proyecta un mundo nuevo. El pensamiento milenarista con su óptica escatológica ofrece una interpretación de los movimientos revolucionarios en tres momentos o etapas: 1) la organización de la guerrilla, cuya finalidad es el cuestionamiento de la realidad por parte de quienes se unen a aquella; 2) la movilización de la sociedad civil, con la reivindicación de los derechos por parte de los grupos sociales oprimidos, 3) el desencanto por la guerrilla, que conduce a la desilusión e incomprensión de los movimientos guerrilleros.
\end{abstract}

ABSTRACT

Latin American Literature ilustrates the repercussion of the guerrilla groups by means of a millenaria doctrine that announces caos and destruction and that projects a new world. The millenarian thougth, with its eschatologic view, proposes an interpretation of the revolutionary movement in three periods or stages: 1) The organizations of the guerrilla, whose finality is the questioning of reality by those who join it. 2) The movilization of the civil society, with the replevin of the rights by the oppressed social groups. 3) The disenchantment for the guerrilla which drives to the disillutionment and misunderstanding of the guerrilla movements.

Partiendo de la idea de que la literatura latinoamericana, con frecuencia, se ha anticipado al pensamiento teológico, el filósofo Horacio Cerruti (1983: 113) analiza cómo la literatura latinoamericana denunciaba situaciones de injusticia y de irrespeto de los derechos fundamentales del hombre, en el marco de un programa político de concientización y de reivindicación de sectores populares. El enfoque cristiano de la salvación del hombre y su idea del advenimiento del Reino de Justicia impregnan los imaginarios políticos de los años 60 y 70 y conducen a una politización de algunos sectores de la Iglesia Católica; su postura crítica y su compromiso directo con los pobres desemboca en la Teología de la Liberación. La dimensión escatológica del cambio aquí y ahora hace que la palabra redentora del cristianismo revolucionario se centre en la concreción de un ideal político. La realidad conflictiva de este mundo en que se vive requiere de un toma de posición y de una acción combativa, tal y como lo enuncia en los años 70 uno de los grandes teólogos de la Liberación: 


\begin{abstract}
Sólo cuando parto desde aquí, puede nacer la esperanza de alcanzar lo "ya realizado" en Cristo. Si no parto desde aquí, la esperanza se convierte en una "espera", inoperante y alienante, de que llegue algún día aquello "ya realizado" (Richard 1975: 26).
\end{abstract}

La esperanza cristiana exige una actitud activa y beligerante contra la opresión y la injusticia, pues el cambio de vida, al cual se compromete el creyente, comienza por asentarse en la tierra, ahí en donde la liberación que nos propone la palabra de Dios coincide y responde a necesidades de una situación concreta cuando la fe se historiza (Casalis 1978). De esta manera, el proyecto cristiano de liberación del hombre y el de la revolución socialista se retroalimentan en el espacio de América Latina.

La denuncia de las estructuras políticas que originan las desigualdades políticas se relaciona con la emergencia de la literatura del testimonio que da cuenta de la historia de aquellos grupos que asumen y promueven un cambio concreto en esas estructuras. Por eso, revolución socialista y liberación cristiana aspiran a una nueva ética que, abandonando un humanismo abstracto o una fe complaciente, historiza los conflictos humanos en términos de una lucha de clases y transforma las relaciones carenciales y asimétricas en búsqueda consciente de la liberación del hombre. La literatura latinoamericana mapea este conflicto mediante un milenarismo que anuncia el caos y la destrucción y pregona la esperanza en el cambio inmediato.

El milenarismo (necesidad de cambio, destrucción de las viejas estructuras) con su óptica escatológica nos ofrece una interpretación de los alcances de los movimientos revolucionarios en nuestro continente en tres momentos o etapas: 1) la organización de la guerrilla, cuya finalidad es el cuestionamiento de la realidad por parte de quienes se unen a aquella; 2) la movilización de la sociedad civil, con la reivindicación de los derechos por parte de los grupos sociales oprimidos, 3 ) el desencanto por la guerrilla, que conduce a la desilusión e incomprensión de los movimientos guerrilleros. Veamos ahora en concreto.

En El cumpleaños de Juan Ángel (1a. edición de 1971), Mario Benedetti escribe una novela en verso, cuyos cambios discursivos se hacen muy apropiados para las transformaciones anunciadas por Juan Ángel con su autobiografía inconclusa. La estructuración del relato pone su énfasis en la conversión ideológica y el rechazo del modelo burgués por parte de Osvaldo Puente. La crisis identitaria del protagonista manifiesta su insatisfacción contra la esclerosis social y las relaciones familiares inauténticas. Quien nace como Osvaldo Puente adopta, ya en la madurez de sus 33 años (77), otro nombre, con el fin de simbolizar su conversión política, dejando todo, patrimonio y familia para enrolarse en la guerrilla urbana: su nueva identidad, Juan Ángel, concreta con su simbolismo el cambio operado en el protagonista. Osvaldo se convertirá en puente, en umbral, en lazo entre una realidad que desea superar y un "espíritu nuevo": "Su apellido, Puente, simboliza el que Osvaldo debe cruzar para convertirse en Juan Ángel: mensajero del espíritu nuevo y testigo de un nuevo compromiso político" (Pérez 1976: 176). Se trata, entonces, de establecer una mediación entre el mundo capitalista y la instauración de la utopía socialista, gracias a la toma de conciencia:

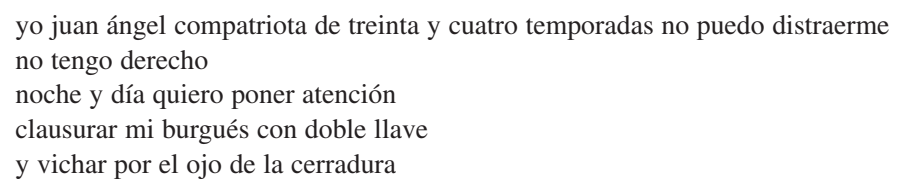




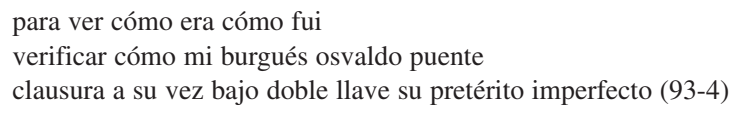

Hay en el protagonista una lucha interior fuerte: el conflicto de acabar con su vida pasada y aceptar la nueva identidad no terminan con sus inquietudes personales; a ello corresponde la decisión que ha tomado de unirse a la guerrilla y acabar de una vez por todas con su antigua identidad. De manera que el nombre Juan Ángel denota la conversión del ungido por Dios (Juan viene del hebreo Yeho-nam "regalo de Dios") y del que viene a ser testigo, es decir, profeta que viene a anunciar la buena nueva de salvación. La transformación de pequeño burgués en guerrillero en esta novela de Mario Benedetti es visto como un camino de aprendizaje que llevará al protagonista hacia la verdad y el conocimiento. Por eso, El cumpleaños de Juan Ángel puede ser interpretado como el testimonio, el evangelio del que ha sido tocado en la gracia hasta dar su misma vida por sus creencias; el ideal revolucionario se actualiza por la fe en el cambio posible:

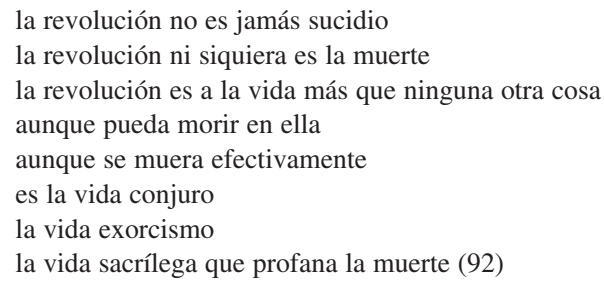

Por lo tanto, en Juan Ángel se da el cumplimiento de la revelación de un nuevo orden que está proximo, el milenarismo anuncia aquí una "ciudad del sol" como una utopía del reino que desean instaurar los guerrilleros en la tierra. A la luz de lo anterior, Juan Ángel es testigo en una doble coordenada: en su biografía personal, gracias a la conversión y a la búsqueda de una vida auténtica; en su dimensión colectiva, porque su experiencia individual retrata la de otros muchos que han decidido también seguir los mismos pasos que él; no es casual que el número de sus compañeros sea con él doce y que, una vez que los descubra la policía, deban huir por un túnel, símbolo de la vida de persecución y de clandestinidad que deberán asumir al final de la novela. El cumpleaños de Juan Ángel es un nuevo evangelio que intenta mostrar la posibilidad del cambio, la alternativa al modelo burgués mediante la conciencia revolucionaria. Impregnado de este cambio, el texto destaca la toma de conciencia y el compromiso del guerrillero como si fuera una lucha contra el mal, aludiendo al verso final del "Padre Nuestro":

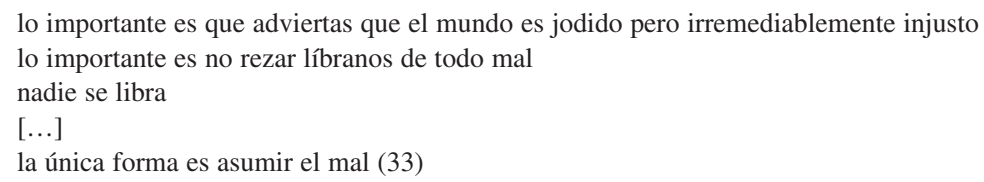

La perspectiva del texto se acerca a la Teología de la Liberación, la lucha por la liberación del hombre comienza en la tierra y apela, por ello, a la conciencia crítica y a la respuesta inmediata: la acción y la lucha contra esa realidad que oprime y destruye al hombre. De ahí que el creyente revolucionario aceptará gustoso el sacrificio de la muerte si viniera el caso de 
dar la vida por los demás. La renuncia y el sacrificio de la muerte resuenan, en las palabras dichas con determinación, como la confirmación de la vida misma, solidaria y fructificante del que se ofrece como víctima por sus compañeros de lucha y por la causa de la Revolución; por ello Juan Ángel recuerda el testimonio ejemplarizante del guerrillero del vietcong:

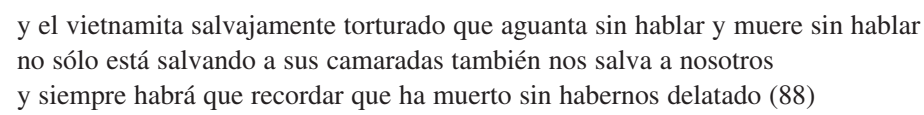

Con ello historiza la lucha armada de los movimientos guerrilleros y apela, más que a la solidaridad de grupo, a la continuidad de la misión histórica que él mismo asume para sí. Así, la apología que se hace del sacrificio revolucionario adquiere un sentido evangélico, haciéndose eco de San Juan 12.25, la muerte y el sacrificio del guerrillero purifica y redime: "El que ama su vida la destruye, y el que desprecia su vida en este mundo la conserva para la vida eterna" (La Biblia Latinoamericana 1979: 209). El creyente revolucionario confirma y exulta esta gran verdad que da nuevo sentido a su existencia; por ello proclama cómo su proyecto de cambio se está llevando a cabo desde ahora:

\footnotetext{
Bienaventurados los ex pobres de espíritu que lleguen a disfrutar esa ecuánime razón pero bienaventurados también nosotros que estamos construyendo unos la hectárea y otros el milímetro cuadrado de esa bienaventuranza (68)
}

Esa esperanza escatológica de la construcción de la utopía socialista tiene que ver con la liberación del hombre de su miseria y de aquello que lo oprime; por eso, El cumpleaños de Juan Ángel se propone como ideario del guerrillero que cree con certeza que se acabará la injusticia y la esclavitud. Por lo tanto, la novela de aprendizaje da cuenta de la conversión del protagonista y se revela como un testimonio de la redención posible para el hombre, siempre y cuando quiera ser auténtico consigo mismo. De ahí que la invitación constante en la novela sea la de actualizar esta misión personal e histórica, pues su dedicatoria adquiere implicaciones políticas, al dirigirse al guerrillero Raúl Sendic, "el líder tupamaro en quien encarnó el movimiento con mayor fuerza, y a quien Benedetti conocía desde joven" (Ruffinelli 1992: 42). El elogio particularizante da cuenta de la efectividad sociopolítica que desea motivar Benedetti, pues la conversión de Osvaldo Puente y su adopción del ideal revolucionario se reduplica en casos concretos, de manera que la buena nueva ha caído en tantos Juan-Ángeles o Raúles Sendics que muestran su determinación y su fe en la causa revolucionaria.

En el caso de Un día en la vida (publicada en 1977), Manlio Argueta denuncia los atropellos y la injusticia social de los sectores marginados de El Salvador, en un momento en que también se le pedía al escritor un compromiso abierto y franco contra los regímenes militares y dictatoriales. Su novela rescata del olvido la voz de los sujetos subalternos y se ofrece como memoria histórica de un conflicto de clase, en el que las movilizaciones populares se nutren de esa coalición entre grupos guerrilleros y organizaciones campesinas (Beoth y Walker: 95). Constituido por fragmentos de monólogos interiores o de discurso autobiográfico, Un día en la vida es de una técnica sencilla y el relato se da de forma transparente para lograr una carga de efectividad y de identificación con el mundo cotidiano de los campesinos salvadoreños y con el rescate del espacio familiar en un mundo convulso cuyo escenario es la cruenta guerra 
civil salvadoreña. Se trató de la respuesta que dio el régimen a la movilización popular; su concretización fue la represión, materializada en torturas, arrestos y fusilamientos (95).

La novela es crónica cotidiana de un "día" paradigmático en "la vida" de una familia campesina y de sus vecinos; pero su efectividad política hace desbordar lo eminentemente privado para convertirse en historia de "la vida" de El Salvador; veamos lo que dice Manlio Argueta en una entrevista:

El problema de El Salvador es un problema latinoamericano, aún con sus más profundas contradicciones, el sueño del pueblo salvadoreño es el sueño de los latinoamericanos (Blanco 1983: 4).

Al contextualizar el alcance de su novela, Argueta transforma la denuncia de los maltratos y las injusticias hacia el campesinado en un testimonio colectivo. Para ello se vale de un relato caleidoscópico, que conjuga las voces de cuatro mujeres, Lupe, Ma. Romelia, Ma. Pía y Adolfina, miembros de una familia, dentro de una sucesión temporal. Con una pluralidad de narradores que se acercan inmediatamente al lector con sus vivencias y recuerdos, $U n$ día en la vida se sitúa en el terreno de la memoria, haciendo que la conciencia biográfica de cada personaje construya una historia no oficial, imagen y autorrepresentación de su devenir. Los grupos no favorecidos no han hecho nunca la Historia; su consecuencia, impide el acceso y la representación de los grupos subalternos (González 1986: 26) y ha creado silencios. Es aquí en donde la crónica del campesinado hecha por Manlio Argueta cobra su sentido, porque en la novela se dejan oír las voces de "La autoridad" y de un "Ellos" que critican duramente la actividad política de los campesinos tildándolos de comunistas ayudados por el sector de la Iglesia Católica comprometida con los pobres. Un día en la vida nos propone la concientización histórica que desnuda el poder de un régimen militar (Narváez 1994: 30), para el cual la lucha en contra de los grupos guerrilleros y de los campesinos que se rebelan se considera una guerra santa o cruzada religioso-militar. Así, reconstruir la voz silenciada empieza por la toma de conciencia y esto se produce al inicio de la novela:

\footnotetext{
Casi todos somos pobres pero no lo tomamos como una desgracia. Ni lo admitimos como algo meritorio. Nunca nos ha importado porque desde hace muchos años, cientos de años, la vida ha pasado igual, sin mayores cambios, todos nos conocemos y nos tratamos de igual a igual, lo mismo vale el que tiene carreta como el que sólo tiene su machete para trabajar (21).
}

Las palabras de Lupe, la abuela, son fundamentales: señalan cómo el sometimiento de los campesinos ha sido absoluto al punto de aceptarlo como propio de su condición. Sin embargo, este conformismo (ver la pobreza como una mancha que los acompaña) empieza a cuestionarse con la novela. El campesinado toma conciencia de que el proceso de opresión, de "cientos de años" como dice Lupe, no tiene razón de ser y una Iglesia imbuida en la Teología de la Liberación lo desenmascara; la salvación del hombre exige tomar conciencia de las injusticias históricas de los terratenientes, alegan con su prédica diferente. En esta liberación del oprimido, como diría Paulo Freire, la primera toma de conciencia es aquella que ata al hombre a la pobreza endémica y lo obliga a exigir derechos mínimos. Lupe nos relata así su proceso de concientización:

Hasta que de pronto, los curas fueron cambiando. Nos fueron metiendo en movimientos cooperativistas, para hacer el bien al otro, a compartir las ganancias. Es una gran cosa hacer el bien a los otros, vivir en paz todos, conocerse todos, levantarse antes que el sol para ir a trabajar con los cipotes [...]. Ahora todo es en 
serio en la misa pues los padres comenzaron a abrirnos los ojos y oídos. Uno de ellos nos repetía siempre: para ganarnos el cielo debemos luchar por hacer el paraíso en la tierra (24-5).

Estos "nuevos curas" invitan al campesinado a abandonar su posición de conformismo enajenante ante una realidad social injusta. Tenemos aquí la posición de un sector de la Iglesia Católica que se politiza y ofrece una interpretación del mundo desde una perspectiva clasista y propone un nuevo significado a la fe: se trata de repensar su existencia de pobres en términos de víctimas del poder político. Con ello, Un día en la vida retoma el proceso de concientización del campesinado salvadoreño, el cual coincide, históricamente, con la introducción de la Teología de la Liberación en la década de los 70 y la aparición del movimiento de Frente Farabundo Martí. La cruenta guerra civil que sigue opondrá a la oligarquía y a las fuerzas armadas contra la guerrilla; en medio quedará el campesinado. La novela se inicia, en efecto, con un hecho de sangre: los asesinatos y desapariciones de los hombres de la familia de Lupe a manos del ejército: Chepe, el marido de Lupe; Justino, su hijo; su yerno Helio Hernández y padre de Alfonsina. La muerte y la violencia recubren tres generaciones de la familia de Lupe, insistiendo en que son los campesinos los que sufren los vejámenes de la contienda.

Por ello, la amplificación del dolor de Lupe y de su familia se transforma en ejemplo paradigmático de la toma de conciencia de las injusticias y de la situación de víctimas del régimen; emerge un "nosotros" que, como sujeto colectivo, condensa el sufrimiento actual e identifica en el presente el comienzo de la rebelión de las mentes. Las palabras de Lupe son candentes ante el recuerdo de su esposo muerto:

\footnotetext{
Por eso los problemas no tienen solución por la respuesta de una sola persona, sino por la respuesta de todos nosotros, los humildes. Los claros. Esto es muy importante: podés ser humilde y vivir en la oscuridad. La cosa, pues, no consiste en ser o no ser humilde. El problema está en la conciencia de cada uno. La conciencia que tengamos. Entonces la vida se hace como el agua clara de los ríos (118).
}

El proceso de concientización y el de liberación van de la mano. Llama poderosamente la atención la metáfora de la luz, símbolo evangélico del compromiso cristiano y del triunfo de la verdad sobre las fuerzas del mal. Cuando Jesús proclama, en San Juan 8.12-47, que Él es la luz del mundo, está anunciando que únicamente la aceptación de su mensaje puede redimir al hombre y ordenar su vida: "Mediante esa luz, adquiere [el hombre] la capacidad de ordenar su existencia [...]. También, mediante esta luz, logrará triunfar sobre todo lo oscuro que lleva en sí mismo" (La Nueva Biblia Latinoamericana 1979: 197). Por eso, la luz se asocia en la novela con el proceso de concientización, en el sentido de que, como lo afirma la Teología de la Liberación, el oprimido historiza su sufrimiento y encuentra, en la recapitulación autobiográfica (Starobinski 1974: 67), que su vida adquiere nuevo sentido. Esto es lo que ocurre con Lupe; el acto de recordar es para Lupe un trabajo de conciencia lúcida que reinterpreta el pasado para asumir (forjar) su destino:

Pensamos más de la cuenta en la esperanza. Como la luz del candil, es. No podíamos ver en la oscuridad. Despuesito es que José comenzó a decirme: la esperanza mantiene al tonto. Yo nunca le he creído. Entiendo hacia dónde va, pero no le tomo al pie de la letra sus palabras. La esperanza nos alimenta. No la esperanza del tonto. La esperanza de uno, cuando se está claro. La conciencia (135-6). 
Esta conciencia recobrada se transforma en rebelión en las otras voces narrativas y hacen que la historia privada de Lupe desborde hacia un plano colectivo. Magistralmente se relacionan en la novela el dolor familiar, el recuerdo de José y la desaparición ahora de Justino con los sucesos políticos que narra Ma. Romelia (el mítin de San Salvador como protesta por el alza de los insumos agrícolas) o Adolfina (la toma de la Catedral de San Salvador). La toma de conciencia lleva a la movilización social y, por ello, los campesinos son perseguidos. Así, para voces narradoras como Ma. Pía o Adolfina, la lucha contra la explotación social es un compromiso moral del pueblo salvadoreño; oigamos a Adolfina: Mi mamá dice que soy rebelde; pero mi papá siempre me ha dicho que a eso no se le debe llamar rebeldía
sino conciencia [...]. He ido comprendiendo la vida, el origen de nuestras pobrezas [...] (108-9).

Lo mismo piensa Ma. Romelia cuando se dirige a su mamá también: "Si no se trata de pedir por pedir, sino de reclamar nuestro derecho" (41). Conciencia de sus derechos y esperanza de un futuro mejor, he aquí los dos pilares sobre los cuales se construye la autorrepresentación del campesinado en Un día en la vida. La reescritura de la historia oficial pasa por una toma de conciencia de la explotación y de la exclusión en un texto en que la situación del oprimido se interpreta desde un proceso de persecución que hace pensar en las primeras comunidades cristianas: su dolor se historiza y testimonia la perspectiva de la utopía realizable.

Con Lituma de los Andes, Mario Vargas Llosa ganó, en 1993, el respetadísimo Premio Planeta. Aunque no descolla ni por su construcción ni por el juego del lenguaje, elementos que hicieron de Vargas Llosa uno de los abanderados de la metaficcionalidad y de la complejidad enunciativa, Lituma de los Andes sí entronca con la producción vargallosiana gracias a esa crítica de la historia y de la realidad latinoamericanas. Ofrece una interpretación del Perú contemporáneo que, por su desarrollo y por sus repercusiones simbólicas, es la extensión de $L a$ guerra del fin del mundo (1981) y de Historia de Mayta (1984). Las dos novelas mencionadas tienen como eje la idea de un milenarismo escatológico en el que, de la destrucción y del caos, vendrá la purificación que traerá el Reino de Justicia y de Libertad ansiado por todos. Se trata de la expresión de una de las formas más auténticas del imaginario colectivo, en el que religión y política se imbrican para radiografiar las crisis sociales. La guerra del fin del mun$d o$, novela que desarrolla el punto de vista de un milenarismo religioso en los sertones brasileños, en el que la guerra de liberación y la fundación de la Canudos celestial son vistas para denunciar los fanatismos (Zorrozúa 1999: 112). En ella encontramos la figura de Antonio Consejero, quien se rebela contra el poder establecido pregonando una nueva sociedad que recupere los valores perdidos. La historia de Mayta se centra en la figura de un hombre que proyecta y prepara una revolución, ya que está obsesionado con la idea de acabar con la injusticia social por medio de un cambio radical; Mayta, el protagonista, es un hombre mestizo con nombre indígena y representa a un amplio sector del pueblo peruano insatisfecho con su destino y con la falta de posibilidades de desarrollo

Por lo tanto, lo que tienen en común estas dos novelas es el desarrollo del principio escatológico, cuya realización textual toma la forma de un mundo en crisis y a punto de destruirse a causa de una revolución, léase, como una transformación que acarrea la destrucción y la crisis. En este sentido, Lituma de los Andes es sólo la continuación de este ciclo milenarista, en 
el que la retórica de la violencia y el proceso de victimización desencadenan la búsqueda de víctimas expiatorias. Efectivamente, la novela comienza en su contigüidad con dos sucesos que deben asociarse entre sí. Suceden inexplicablemente tres desapariciones sin dejar rastro y el cabo Lituma debe aclararlas en tanto representante de la ley. El cabo Lituma y su subalterno, el guardia Tomás Carreño, temen que hayan sido asesinados respectivamente: el mudito, Pedro Tinoco, quien se ocupaba de las labores domésticas en la comisaría; Casimiro Huarcaya, el albino; y un capataz de cuadrilla, Medardo Llantac, quien trabajaba en la construcción de la carretera hacia Huancayo, una ciudad en la sierra andina. Al principio, desconcertado por la triple desaparición, Lituma piensa en dos opciones: o es la guerrilla del Sendero Luminoso quien los ha ajusticiado pensando para sus adentros que "'Ya los tenemos encima a los terrucos' [...] 'Cualquier noche vendrán"” (12), o en su desesperación por el mutismo y la poca colaboración de los habitantes de Naccos, incluido los peones del campamento y los indios comuneros, lanza la siguiente pregunta: “Se los habían tragado los cerros, entonces?” (12).

El otro incidente es la desaparición de dos turistas franceses, Albert y Michèle, quienes han decido hacer el viaje a Cusco por bus y en el camino guerrilleros del Sendero Luminoso los interceptan para hacer una toma de prisioneros; los turistas intentan pasar desapercibidos, pero los guerrilleros los capturan y presencian cómo al único viajero no extranjero, compañero de infortunio, lo lapidan en forma sangrienta (25). Más tarde por medio del cabo Lituma sabemos que los dos turistas franceses han muerto de la misma forma (45). La novela comienza, entonces, con una pesquisa policial en la que el cabo Lituma pone todo su esfuerzo para esclarecer los tres asesinatos no resueltos, el asesinato de los turistas franceses únicamente es una pieza en este engranaje de violencia y de retórica persecutoria en el afloran los antagonismos de la realidad peruana actual. Al principio de la novela, para explicar la desaparición de las tres personas, Lituma responsabiliza a los "terrucos", el Sendero Luminoso, o a las fuerzas de naturaleza, el haberse cobrado estas vidas; tenía toda la razón. Veamos.

El levantamiento del movimiento Sendero Luminoso, comandados por Abigaíl Guzmán, hace temblar a la sociedad peruana de los años 80 y permite ver las contradicciones estructurales de un país oligárquico, en donde la marginalidad y los desbalances entre la sierra y la costa son visibles, y las relaciones sociales son rígidamente clasistas, herencia de la época colonial. El Sendero Luminoso pregona un cambio revolucionario contra las fuerzas hegemónicas que gobiernan la situación de injusticia y de explotación de los indígenas y contra todos aquellos que de alguna manera apoyan el sistema. Muy pronto, sus ideas degeneran y pierden de vista al verdadero enemigo, asesinando a indígenas inocentes y sembrando el caos y la destrucción en la sierra andina. De ahí la intolerancia y la persecución en contra de todo aquello que podría aparecer como obstáculo o rival de sus pretensiones de llegar a la Revolución ansiada. En este contexto de crisis se desarrolla la novela para marcar la desilusión de Vargas Llosa ante los movimientos guerrilleros.

Ante un mundo que se erosiona y se destruye, M. Valotta (1988) ha analizado en su hermoso libro El fin del mundo en la mitología indígena americana cómo la llegada del español exacerbó los principios escatológicos que contenían las mitologías indígenas, haciendo que interpretaran la conmoción social que provocó la Conquista como una catástrofe apocalíptica ${ }^{2}$, por lo cual se acrecentó la resistencia cultural a abrazar la nueva religión católica. En el caso del mundo indígena, la oposición al conquistador se vio catalizada en un mesianismo, como acota Valotta: "el mundo andino produjo manifestaciones tempranas de conservadurismo cultural, 
cuajado en diversos movimientos de masas de carácter mesiánico [...] y cuando la conquista se tornó un hecho irreversible, el impulso mesiánico se desplazó hacia el mito" (41). Por ejemplo, el cronista F. Guamán Poma de Ayala en su Nueva crónica y buen gobierno explica la Conquista española como un cataclismo cósmico al que debería seguir la regeneración del universo y el advenimiento del "buen gobierno" basado en el regreso al pasado andino. Situado en este milenarismo religioso que ansía la regeneración espiritual y de la vida humana, debemos analizar los crímenes que se cometen en la novela, porque a todas luces tienen todas las características de ser un sacrificio en pos de la regeneración, es decir, de ser víctimas expiatorias para que de la situación conflictiva surja de nuevo el orden.

La clave se encuentra también al principio de novela, cuando después de mostrar su impotencia para resolver los crímenes, ante el cielo de tormenta que acecha la sierra, la instancia narrativa, focalizando el pensamiento de Lituma, aclara que esos truenos son la expresión de las divinidades de la montaña "con unos ronquidos entrecortados que subían desde esas entrañas de la tierra que estos serruchos creían pobladas de toros, serpientes, cóndores y espíritus" (13) y registra en discurso directo la conversación entre Lituma y Tomás:

\footnotetext{
¿De veras los indios creen eso? Claro, mi cabo, si hasta les rezan y les ponen ofrendas. ¿No ha visto los platitos de comida en las abras de la Cordillera? (13).
}

Esta explicación mágica de los fenómenos atmosféricos está ligada a la creencia de que los espíritus ancestrales habitan las cumbres de las montañas; pero lo que más nos interesa aquí es la yuxtaposición en este pensamiento religioso, entre el caos y a la insurrección de los guerrilleros del Sendero Luminoso. El grupo guerrillero hace de las suyas en la sierra y se presentan constantes accidentes que sabotean la construcción de la carretera hacia Huancayo. Veamos lo que dice la bruja doña Adriana:

\footnotetext{
-Todos estos cerros están llenos de enemigos- dijo suavemente. Viven ahí dentro. Se la pasan urdiendo sus maldades día y noche. Hacen daños y más daños. Ésa es la razón de tantos accidentes. Los derrumbes en los socavones. Los camiones a los que se les vaciaron los frenos o les faltó pista en las curvas, Las cajas de dinamita que estallan llevándose piernas y cabezas (44).
}

La destrucción y el sabotaje causado a la compañía que trae la modernidad, la carretera, es interpretada como expresión de una maldad encarnada en los espíritus. Claro está, Lituma no se deja convencer por esta explicación; él sabe que los verdaderos causantes de los accidentes son los guerrilleros y en son de burla le dice a doña Adriana: "-Si todo lo malo es cosa del diablo, no hay casualidades en el mundo [...]. ¿A esos dos francesitos que iban a Andahuaylas los mató a pedradas Satanás, señora? Porque esos enemigos son los diablos, ¿no?” (45). Sin embargo, en el pensamiento mítico, son los espíritus de las montañas quienes se manifiestan haciendo saber su enojo. Prueba de ello son los huaycos, esos aludes gigantescos producidos por los desprendimientos de nieve, rocas y barros que bajan desde lo alto como "trombas de muerte" (45).

Las consecuencias de este milenarismo escatológico no se hacen esperar porque un huayco destruye los avances de la construcción de la carretera y sepulta maquinaria y hombres, produciendo la catástrofe esperada, la cual termina con el cierre de la cantera de trabajo y con los últimos alientos de vida de Naccos, pueblo minero en decadencia. Las fuerzas de las 
montañas se han manifestado para destruir aquello que representa el paso del hombre blanco ante una sierra indómita que no se deja vencer. En este contexto, el huayco y el posterior cierre de la compañía vienen a ser elementos de una retórica escatológica que, dentro de la novela, culmina con el descubrimiento de la verdad acerca de la desaparición de los tres hombres. La última noche que pasa en Naccos, Lituma le arranca con bastante esfuerzo una confesión a uno de los habitantes del pueblo:

\footnotetext{
-¿Los sacrificaron a los apus, no es cierto?-¿A los apus? -preguntó el hombre, moviéndose. [...]- Los espíritus de las montañas -le aclaró Lituma-. Los amarus, los mukis, los dioses, los diablos, como se llamen. Esos que están metidos dentro de los cerros y provocan las desgracias. ¿Los sacrificaron para que no cayera el huayco? ¿Para que no vinieran los terrucos a matar a nadie ni a llevarse a la gente? [...] (308-9).
}

Lituma relaciona la guerra sucia de Sendero Luminoso y el miedo inminente de la destrucción causada por el alud con la necesidad de encontrar culpables a la crisis (aplacar la ira de los dioses de las montañas). Pero lo más revelador son las palabras finales de la persona a quien Lituma interroga; recordemos que los cadáveres de las víctimas nunca habían aparecido y la declaración del paisano evidencia una culpa colectiva reprimida. Es una verdadera confesión del crimen cometido:

\footnotetext{
-Matar sería lo de menos- rugió el hombre tendido [...]. Matar es lo de menos. ¿No se ha vuelto una cojudez, como mear o hacer la caca? No es eso lo que tiene jodida a la gente. No sólo a mí, también a muchos de los que ya se fueron. Sino lo otro.-¿Lo otro?

-Lituma sintió frio.-El gusto en la boca- susurró el barrenero y se le rajó la voz-.

No se va, por más que uno se enjuague. Ahorita lo estoy sintiendo. Aquí en mi lengua, en mis dientes. También en mi garganta. Hasta en la barriga lo siento. Como si acabara de estar masticando (310-1).
}

El sacrificio de las víctimas llega su ejecución perfecta. Los cuerpos ajusticiados e inmolados para neutralizar la destrucción (léase ira de las fuerzas divinas) conduce a los habitantes de Naccos a la comunión perfecta, ingestión de los cuerpos, en un ritual que recuerda la muerte y la vida dentro de un ciclo de regeneración. Pero lo más interesante es el asco y el sentimiento de culpabilidad que acarrean las palabras del barrenero, haciendo que el acto de matar esté al mismo nivel de los otros principios de vida material, en el que los humanos nos acercamos a los animales, según Bajtín. La realidad peruana se deja contaminar de un pensamiento escatológico que hace de la crisis de la sociedad peruana un espacio en el que la única alternativa posible sea buscar víctimas que neutralicen el "fin del mundo" y la crisis colectiva. La posición de Vargas Llosa ante las consecuencias de la guerra civil propiciada por las partes en conflicto es clara; no hay vencedores, todos pierden y se deshumanizan. Por ello, la guerrilla maoísta del Sendero Luminoso aparece como víctimario que no sabe dónde está su enemigo.

Lituma de los Andes desarrolla el esquema de la víctima expiatoria, que para René Girard (1978) es la substitución ficticia de todos los antagonismos de la sociedad, en la figura de un solo individuo que resume en él la hostilidad y la rivalidad que genera toda crisis social. René Girard explica que el mecanismo fundador de las sociedades es la violencia por el poder, lo que él conceptualiza como la rivalidad de dos grupos por un mismo objeto, que ambos codician y quieren apropiarse. Esta rivalidad genera una crisis o una lucha encarnizada y genera una fascinación por los rivales, en lo que Girard denomina la mímesis del antagonista. Claramente, la novela enfoca esta crisis en la figura de los antagonistas, enemigos o rivales, 
que deben eliminarse a como haya lugar, en esa política de sabotaje y de destrucción que el Sendero Luminoso llevó a cabo en el Perú de los años 80. Pero, sobre todo, esta crisis se enfoca en la figura de víctimas expiatorias que puedan detener esa destrucción y aplacar a las divinidades dentro de lo que se considera, en el imaginario mítico indígena andino, como el periodo de espera (de transición) hacia la venida de un nuevo orden. Esa espiral de violencia no se puede detener, cuando los movimientos guerrilleros atentan contra aquellos que desean y dicen defender ${ }^{3}$. El cronotopo del apocalipsis ${ }^{4}$ con su idea del fin del mundo surge para resemantizar tanto las consecuencias de los desastres como la desilusión ante las luchas del Sendero Luminoso. De ahí que los movimientos guerrilleros en Lituma en los Andes sean vistos como un elemento más dentro del proceso de crisis (léase descomposición social y degradación) que ha caído sobre la sociedad peruana; es más, agudiza las contradicciones entre un sistema social injusto, por añadidura endémico, y la necesidades de un cambio posible.

\section{Notas}

1. Una versión anterior se presentó como conferencia en IX Coloquio Anual "Cinco de mayo", celebrado en mayo del 2001, California State University, Stanislaus.

2. El artículo de Zorrozúa me ha conducido a leer el estudio de Valotta, en donde hay que destacar que los mitos cosmológicos tienen en su germen procesos escatológicos de destrucción y de caos.

3. Véase en ese sentido el documentado libro que edita Daniel Castro, citado en la bibliografía.

4. Para un desarrollo del cronotopo apocalíptico remito a la presentación al alimón, citada también en la bibliografía, que hicimos María Amoretti y un servidor sobre la novela de la escritora nicaragüense, $E l$ sueño del ángel (Managua 2001).

\section{Bibliografía}

Amoretti Hurtado, María y Jorge Chen Sham. 2001. "De plumas y ángeles: Presentación al alimón de la doctora María Amoretti Hurtado y el doctor Jorge Chen Sham, ambos de la Universidad de Costa Rica, realizad[a] en ocasión del lanzamiento del libro 'El sueño del ángel'”, de Gloria Elena Espinoza de Tercero". Artes y Letras, sábado 15 de diciembre: 1 y 4 .

Argueta, Manlio. 1982. Un día en la vida. 2a. edición. San José: EDUCA.

Beoth, John A y Thomas W. Walker. "National Revolts in El Salvador and Guatemala". Understanding Central America. 2a. edición. Boulder: Westview Press: 91-115.

Blanco, Patricia. 1983. "Holanda abrió las puertas a Un día en la vida". Semanario Universidad, 19 al 25 de agosto: 4. 
Casalis, George. 1978. "Liberación y concientización en América Latina”. Ideologías de liberación y mensaje de salvación. Christian Metz (Ed.): 151-70.

Castro, Daniel (Ed.). 1999. Revolution and Revolutionaries: Guerrilla Mouvements in Latin America. Wilmington: Schoraly Ressources.

Cerruti Guldberg, Horacio. 1983. Filosofía de la liberación latinoamericana. México, D.F.; Fondo de Cultura económica.

Girard, Réné.1978. Des choses cachées depuis la fondation du monde. París: Bernard Grasset. 1982. Le bouc émissaire. París: Bernard Grasset.

González Ortega, Alfonso. 1986. Lenguaje cotidiano, represión social y conciencia de la propia historicidad. San José: Instituto de Investigaciones Psicológicas de la Universidad de Costa Rica.

Metz, Christian (Ed.). 1978. Ideologías de liberación y mensaje de salvación. Salamanca: Ediciones Sígueme.

Narváez, Carlos Raúl. 1994. “Un día en la vida de Manlio Argueta: La ficción ante el espejo de la historia". Exégesis 7 (19): 28-32.

La Nueva Biblia Latinoamericana. 1979. 23a. edición. Madrid: Ediciones Paulinas/ Estella: Editorial Verbo Divino.

Pérez Beberfall, Freda. 1976. "Simbolismo e ideología en El cumpleaños de Juan Ángel”. Recopilación de textos sobre Mario Benedetti. Ambrosio Fornet (Ed.). La Habana: Casa de las Américas: 175-85.

Richard, Pablo y Estéban Torres. 1975. Cristianismo, lucha, ideología y racionalidad socialista. Salamanca: Ediciones Sígueme.

Ruffinelli, Jorge. 1992. "Benedetti novelista: el tiempo de la (des) esperanza". Anthropos 132: 38-44.

Starobinski, Jean. 1974. La relación crítica (Psicoanálisis y Literatura). Madrid: Ediciones Taurus.

Valotta, M. 1988. El fin del mundo en la mitología indígena americana. Madrid: Fondo de Cultura Económica.

Vargas Llosa, Mario. 1983. Lituma en los Andes. Madrid: Editorial Planeta.

Zorrozúa Eguren, Esther. 1999. “Tres fábulas quiliastas de M.Vargas Llosa”. Letras de Deusto 84 (29): 105-37. 